\title{
Reliability and Availability Analysis of Arepairable System with Two Types of Failure
}

\author{
M. A. El-Damcese, M. S. Shama
}

Department of Mathematics, Faculty of Science, Tanta University, Egypt

\begin{tabular}{|c|c|}
\hline Article Info & ABSTRACT \\
\hline Article history: & This paper investigates reliability and availability of a repairable system with \\
\hline Received Dec 20, 2014 & $\begin{array}{l}\text { two types of failure. Let failure rate and repair rate of [type1, type2] } \\
\text { components are assumed to be exponentially distributed. The expressions of }\end{array}$ \\
\hline Revised Feb 5 20, 2015 & availability and reliability characteristics such as the system reliability and \\
\hline Accepted Feb 20, 2015 & $\begin{array}{l}\text { the mean time to failure are derived. We used several cases to analyze } \\
\text { graphically the effect of various system parameters on the reliability system }\end{array}$ \\
\hline Keyword: & \\
\hline
\end{tabular}

Availability

Mean time to system failure

Reliability

\section{Corresponding Author:}

M. A. El-Damcese,

Department of mathematics,

Faculty of science,

Tanta University, Egypt.

Email: m_shama87@yahoo.com

\section{INTRODUCTION}

Redundancy is one of the ways to increase the reliability of a system. There are mainly three types of standby redundancy: hot standby, cold standby, and warm standby. A hot standby component has the same failure rate as the active component while a cold standby component has zero failure rate.

Recently El-Damcese and Shama studied Reliability and availability analysis of a standby repairable system with degradation facility in reference [10] and Reliability measures of a degradable system with standby switching failures and reboot delay in reference [11] but in this paper we discuss a repairable system with two types of failure. In the past decades, many articles concerning the reliability and availability of standby systems have been published. Among them. Galikowsky et al., [1] analyzed the series systems with cold standby components. Wang and Sivazlian [2] examined the reliability characteristics of a multipleserver $(\mathrm{M}+\mathrm{W})$ unit system with exponential failure and exponential repair time distributions. Ke. et al., [3] studied the reliability measures of a repairable system with warm standby switching failures and reboot delay. Ke, et al., [5] analyzed the machine repair problem with unreliable multi-repairmen. Wang, et al., [6] considered the single server machine repair problem with working vacation. Wang, et al., [4] introduced the warm-standby machine repair problem with Balking, reneging and standby switching failures. Hsu, et al., [7] examined an availability system with reboot delay, standby switching failures and an unreliable repair facility, which consists of two active components and one warm standby. Jain, et al., [8] studied the degraded model with warm standbys and two repairmen. Wang, et al., [9] compared four different system configurations with warm standby components and standby switching failures.

There are two objectives of this paper. The first objective is to develop the explicit expressions for availability function, reliability function and mean time to failure using Laplace transform techniques. The 
second objective is to perform a parametric investigation which presents numerical results to analyze the effects of the various system parameters on the system reliability and system availability.

\section{NOTATIONS}

$M:$ the number of operating units in the initial state.

$W$ : the number of cold standby units in the initial state.

$R_{1}$ : the number of repairman in the first service line.

$R_{2}:$ the number of repairman in the second service line.

$\lambda_{1}$ : the failure rate of type 1 .

$\lambda_{2}:$ the failure rate of type2.

$\mu_{1}$ : the repair rate of type 1 .

$\mu_{2}:$ the repair rate of type 2 .

$\mu_{1, n}$ : mean repair rate when there are $\mathrm{n}$ failed units of type1.

$\mu_{2, n}$ : mean repair rate when there are $\mathrm{n}$ failed units of type2.

$P_{i, j}(t)$ : probability that there are i failed units of type 1and $\mathrm{j}$, failed units of type 2 in the system at time $\mathrm{t}$ where:

$i, j=0,1,2, \ldots, W, 0 \leq i+j \leq W+1$.

$s$ : Laplace transform variable.

$P_{i, j}^{*}(t)$ : Laplace transform of $P_{i, j}(t)$.

$Y \quad$ : time to failure of the system.

$A_{Y}(t)$ : availability function of the system.

$R_{Y}(t)$ : reliability function of the system.

$M T T F$ : mean time to failure.

\section{PROBLEM DESCRIPTION}

We consider a machining system consisting of $M$ identical units operating simultaneously in parallel, $W$ cold standby units, $R_{1}$ repairmen in the first service line who repair failed units of type 1 and $R_{2}$ repairmen in the second service line who repair failed units of type2. To develop the mathematical model for the system, and the assumptions of the model are described as follows. We suppose that the failure rate of type 1 and type 2 occur independently of the states of other units and follow exponential distributions with $\lambda_{1}, \lambda_{2}$, respectively.

An operating unit replaced by a cold standby if and only if it failed [type1 or type2] and one cold standby unit is available, and then it is immediately sent to the appropriate service line where it is repaired with time-to-repair which is exponentially distributed with parameter $\mu_{1}$ or $\mu_{2}$ according to the type of failure. Moreover, we assume that the secession of failure times and repair times are independently distributed random variable. Let us assume that failed units [type1 or type2] arriving at the repairmen form a single waiting line and are repaired in the order of their breakdowns; i.e. according to the first-come, firstserved discipline. Suppose that the repairmen in the two service lines can repair only one failed unit at a time and the repair is independent of the failure of the units. Once a unit is repaired, it is as good as new. System availability is investigated according to the assumptions that system is safe when all $M$ operating units are working. 


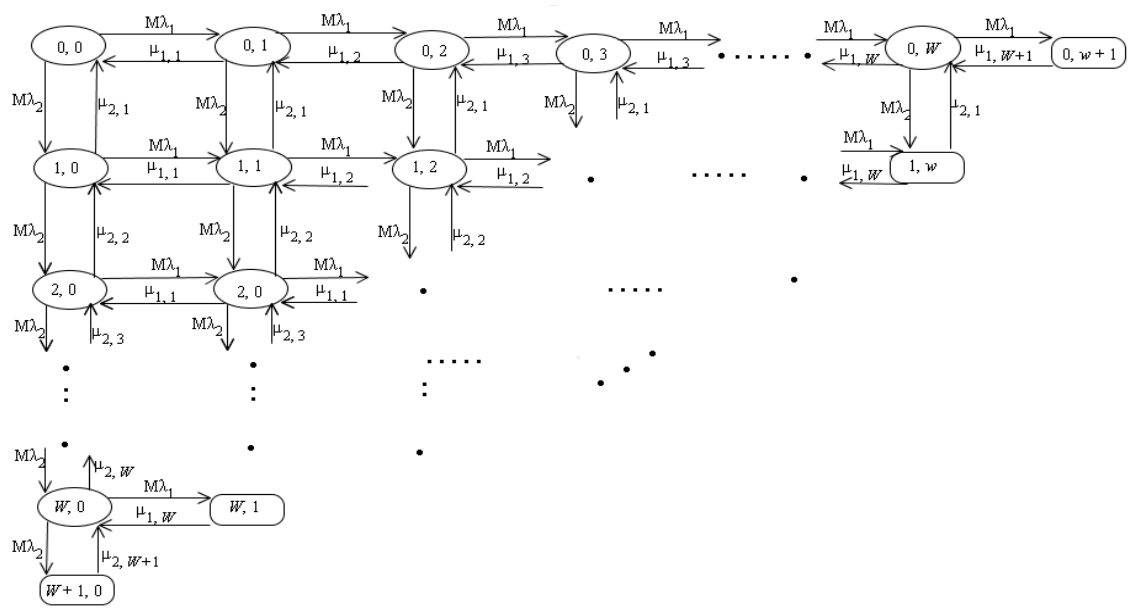

Figure 1. State-transition-rate diagram

\section{AVAILABILITY AND RELIABILITY ANALYSIS OF THE SYSTEM}

At time $t=0$ the system start operation with no failed units. The availability function under the exponential failure time and exponential repair time distributions can be developed through the birth -death process. Let $Y$ be the random variable representing the time to failure of the system.

The mean repair rate $\mu_{1, n}$ is given by:

$$
\mu_{1, n}= \begin{cases}n \mu_{1}, & \text { if } 1 \leq \mathrm{n} \leq \min \left(\mathrm{R}_{1}, \mathrm{~W}\right) \\ R_{1} \mu_{1} & , \quad \text { if } \mathrm{R}_{1} \leq \mathrm{n} \leq \mathrm{W} \\ 0 & \text { otherwise }\end{cases}
$$

The mean repair rate $\mu_{2, n}$ is given by:

$$
\mu_{2, n}= \begin{cases}n \mu_{2} & , \quad \text { if } 1 \leq \mathrm{n} \leq \min \left(\mathrm{R}_{2}, \mathrm{~W}\right) \\ R_{2} \mu_{2} & , \quad \text { if } \mathrm{R}_{2} \leq \mathrm{n} \leq \mathrm{W} \\ 0 & \text { otherwise }\end{cases}
$$

The Laplace transforms of $P_{i, j}(t)$ are defined by:

$$
P_{i, j}^{*}(s)=\int_{0}^{\infty} e^{-s t} P_{i, j}(t) d t, i, j=0,1,2, \ldots, W \quad, 0 \leq i+j \leq W+1 .
$$

State -transition-rate diagram can be obtained in Fig.1-1, and it leads to the following Laplace transform expressions for $P_{i, j}^{*}(s)$ :

$$
\begin{aligned}
& \left(s+M \lambda_{1}+M \lambda_{2}\right) P_{0,0}^{*}(s)-\mu_{1,1} P_{0,1}^{*}(s)-\mu_{2,1} P_{1,0}^{*}(s)=1 \\
& \left(s+M \lambda_{1}+M \lambda_{2}+\mu_{1, n}\right) P_{0, n}^{*}(s)-\mu_{2,1} P_{1, n}^{*}(s)-\mu_{1, n+1} P_{0, n+1}^{*}(s)- \\
& M \lambda_{1} P_{0, n-1}^{*}(s)=0, \quad 1 \leq n \leq W-1 \\
& \left(s+\mu_{1, W+1}\right) P_{0, W+1}^{*}(s)-M \lambda_{1} P_{0, W}^{*}(s)=0
\end{aligned}
$$


$\left(s+M \lambda_{1}+M \lambda_{2}+\mu_{2, u}\right) P_{u, 0}^{*}(s)-M \lambda_{2} P_{u-1,0}^{*}(s)-\mu_{1,1} P_{u, 1}^{*}(s)$

$-\mu_{2, u+1} P_{u+1,0}^{*}(s)=0,1 \leq u \leq W-1$

$\left(s+M \lambda_{1}+M \lambda_{2}+\mu_{2, W}\right) P_{W, 0}^{*}(s)-M \lambda_{2} P_{W-1,0}^{*}(s)$

$-\mu_{2, W+1} P_{W+1,0}^{*}(s)=0$

$\left(s+\mu_{1, W-u+1}+\mu_{2, u}\right) P_{u, W-u+1}^{*}(s)-M \lambda_{1} P_{u, W-u}^{*}(s)$

$-M \lambda_{2} P_{u-1, W-u+1}^{*}(s)=0,1 \leq u \leq W$

$\left(s+\mu_{2, W+1}\right) P_{W+1,0}^{*}(s)-M \lambda_{2} P_{W, 0}^{*}(s)=0$

$\left(s+M \lambda_{1}+M \lambda_{2}+\mu_{1, W}\right) P_{0, W}^{*}(s)-M \lambda_{1} P_{0, W-1}^{*}(s)-\mu_{2,1} P_{1, W}^{*}(s)$

$-\mu_{1, W+1} P_{0, W+1}^{*}(s)=0$

$\left(s+M \lambda_{1}+\mu_{2, u+1}+M \lambda_{2}+\mu_{1, n}\right) P_{u+1, n}^{*}(s)-\mu_{1, n+1} P_{u+1, n+1}^{*}(s)$

$-M \lambda_{2} P_{u, n}^{*}(s)-M \lambda_{1} P_{u+1, n-1}^{*}(s)-\mu_{2, u+2} P_{u+2, n}^{*}(s)$,

$0 \leq u \leq W-3, \quad 1 \leq n \leq W-u-2$

$\left(s+M \lambda_{1}+\mu_{2, u}+M \lambda_{2}+\mu_{1, W-u}\right) P_{u, W-u}^{*}(s)-M \lambda_{2} P_{u-1, W-u}^{*}(s)$

$-M \lambda_{1} P_{u, W-u-1}^{*}(s)-\mu_{1, W-u+1} P_{u, W-u+1}^{*}(s)-\mu_{2, u+1} P_{u+1, W-u}^{*}(s)$,

$1 \leq u \leq W-1$

By solving equations (1a)-(1j) and taking inverse Laplace transforms (using maple program). We obtain the availability function as follows:

$$
A_{Y}(t)=L^{-1}\left(\sum_{i+j=0}^{W+1} P_{i, j}^{*}(s)\right)=\left(\sum_{i+j=0}^{W+1} P_{i, j}(t)\right)
$$

Where $i, j=0,1,2, \ldots, W$.

The steady-state availability probability can be obtained from the following relation.

$$
A=\lim _{t \rightarrow \infty} A(t)
$$

To obtain the reliability function of model (1a)-(1j), we assume that all failed states of the system are absorbing states and set all transition rates from these states equal to zero. We also consider that $P_{i, j}(t) \rightarrow \hat{P}_{i, j}(t)$ the reliability function can be obtained by taking the inverse of Laplace transform as follows.

$$
R_{Y}(t)=L^{-1}\left(\sum_{i+j=0}^{W+1} \hat{P}_{i, j}^{*}(s)\right)=\left(\sum_{i+j=0}^{W+1} \hat{P}_{i, j}(t)\right)
$$

The mean time to failure $M T T F$ can be obtained from the following relation. 


$$
\text { MTTF }=\lim _{s \rightarrow 0} R_{Y}^{*}(s)=\lim _{s \rightarrow 0}\left\{\sum_{i+j=0}^{M+W} \hat{P}_{i, j}^{*}(s)\right\}=\left\{\sum_{i+j=0}^{M+W} \hat{P}_{i, j}^{*}(0)\right\}
$$

We perform a sensitivity analysis for changes in the reliability of the system $R_{Y}(t)$ from changes in system parameters $\lambda_{1}, \lambda_{2}, \mu_{1}$ and $\mu_{2}$.by differentiating equation (1.4) with respect to $\lambda_{1}$ we obtain:

$$
\frac{\partial R_{Y}(t)}{\partial \lambda_{1}}=\frac{\partial}{\partial \lambda_{1}}\left\{\sum_{i+j=0}^{M+W} \hat{P}_{i, j}(t)\right\}=\left\{\sum_{i+j=0}^{M+W} \frac{\partial}{\partial \lambda_{1}} \hat{P}_{i, j}(t)\right\}
$$

We use the same procedure to get $\frac{\partial R_{Y}(t)}{\partial \lambda_{2}}, \frac{\partial R_{Y}(t)}{\partial \mu_{1}}, \frac{\partial R_{Y}(t)}{\partial \mu_{2}}$.

\section{NUMERICAL RESULTS}

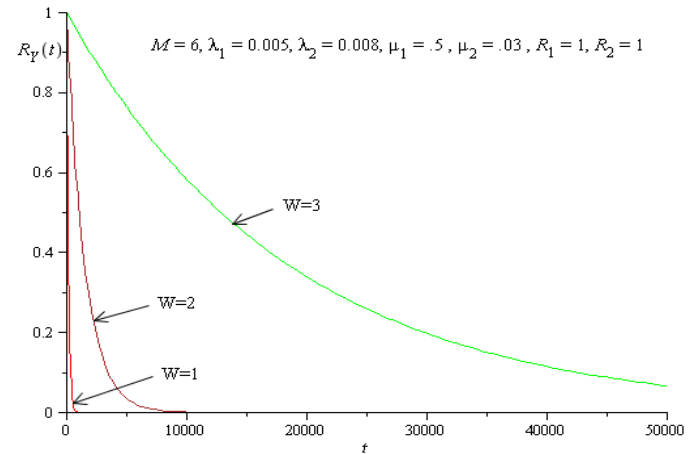

Figure 1. System reliability for different numbers of standby units

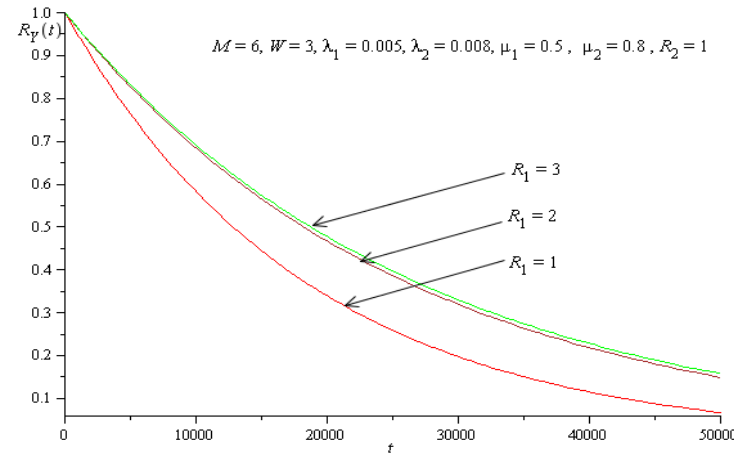

Figure 2. System reliability for different numbers of repairmen in first service line

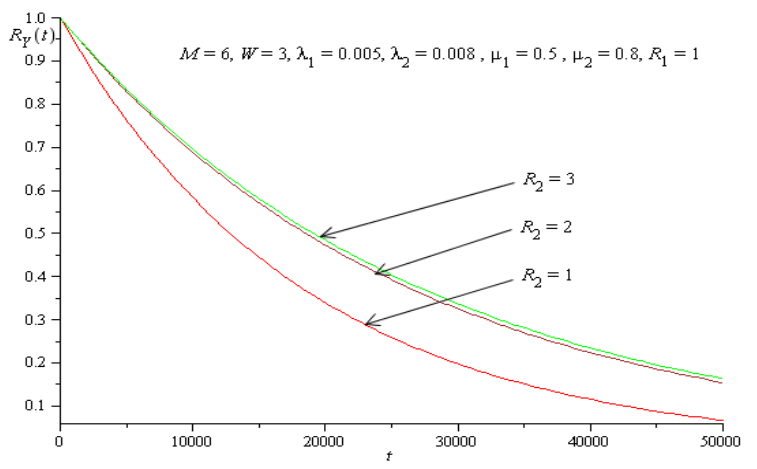

Figure 3. System reliability for different numbers of repairmen in second service line

In this section, we use MAPLE computer program to provide the numerical results of the effects of various parameters on system reliability and system availability.

We choose $\lambda_{1}=0.005, \lambda_{2}=0.008$ and fix $\mu_{1}=0.5, \mu_{2}=0.8$. The following cases are analyzed graphically to study the effect of various parameters on system reliability.

Case1: Fix $M=6, R_{2}=1, R_{1}=1$ and choose $W=1,2,3$.

Case 2: Fix $M=6, W=3, R_{2}=1$, and choose $R_{1}=1,2,3$. 
Case3:Fix $M=6, W=3, R_{1}=1$, and choose $R_{2}=1,2,3$.

It can be observed from Figure 1, Figure 2 and Figure 3 that the system reliability increases as $W$ increases or $R_{1}$ increase or $R_{2}$ increase.

Next we analyze the impact of failure rate $\lambda_{1}$ and failure rate $\lambda_{2}$ on the availability .As presented in Figure 4 we find that system availability $A_{Y}(t)$ becomes better when failure rate $\lambda_{2}$ equal zero than when failure rate $\lambda_{1}$ equal zero and steady availability doesn't change.

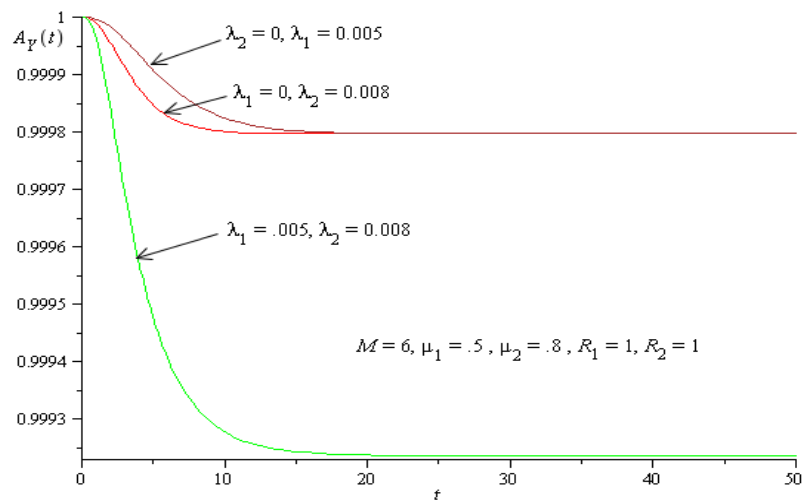

Figure 4. System availability for different failure rates $\left(\lambda_{1}\right.$ and $\left.\lambda_{2}\right)$

\section{CONCLUSION}

In this paper, a mathematical model was constructed for a repairable system with two types of failure. Availability, reliability and mean time to system failure for the system reliability were obtained and the results were shown graphically by the aid of MAPLE program. Results indicate that the reliability of the system reliability increases by increasing of cold standby units, $R_{1}$ and $R_{2}$.

\section{REFERENCES}

[1] Galikowsky C., et al., "Optimal redundancies for reliability and availability of series systems", Microelectronics and Reliability, Vol. 36, pp. 1537-1546, 1996.

[2] Wang K. H., and Sivazlian B. D., "Reliability of a system with warm standbys and repairmen", Microelectronics and Reliability, Vol. 29, pp. 849-860, 1989.

[3] Ke J. B., et al., "Reliability Measures of a Repairable System with Standby Switching Failures and Reboot Delay", Quality Technology \&Quantitative Management, Vol. 8, No. 1, pp. 15-26, 2011.

[4] Wang K. H., et al., "Profit analysis of the M/M/R machine repair problem with balking, reneging, and standby switching failures. Computers and Operations Research, Vol. 34, pp. 835-847, 2007.

[5] Ke J. C., et al., "Computational analysis of machine repair problem with unreliable multi-repairmen", Computers \&Operations Research, Vol. 40, pp. 848-855, 2013.

[6] Wang K. H., et al., "Optimal management of the machine repair problem with working vacation: New ton's method", Computational and Applied Mathematics, pp. 449-458, 2009.

[7] Hsu Y. L., et al., "Standby system with general repair, reboot delay, switching failure and unreliable repair facility A statistical standpoint", Mathematics and Computers in Simulation, Vol. 81, pp. 2400-2413, 2011.

[8] Jain M., Rakhee, and Singh M, "Bilevel control of degraded machining system with warm standbys, setup and vacation", Applied Mathematical Modeling, Vol. 28, pp. 1015-1026, 2004.

[9] Wang K. H., et al., "Comparison of reliability and the availability between four systems with warm standby components and standby switching failures", Applied Mathematics and Computation, Vol. 183, pp. 1310-1322, 2006.

[10] El-Damcese M. A., and Shama M. S., "Reliability and availability analysis of a standby repairable system with degradation facility", International Journal of Research and Reviews in Applied Sciences, Vol. 16, pp. 501-507, 2013.

[11] El-Damcese M. A., and Shama M. S., "Reliability measures of a degradable system with standby switching failures and reboot delay", Applied Mathematics in Engineering, Management and Technology, Vol. 1, pp. 1-16, 2013. 